Revista de
Economild
Contemporâned

\title{
DISPARIDADE SOCIOECONÔMICA E FLUXO MIGRATÓRIO CHINÊS: INTERPRETAÇÃO DE EVENTOS CONTEMPORÂNEOS SEGUNDO OS CLÁSSICOS DO DESENVOLVIMENTO
}

\author{
Frederick Fagundes Alves ${ }^{a}$ \\ Silvia Harumi Toyoshima ${ }^{b}$ \\ ${ }^{a}$ Estudante de Doutorado em Economia Aplicada pelo Programa de Pós-graduação em Economia \\ Aplicada da Universidade Federal de Viçosa (PPGEA/UFV).

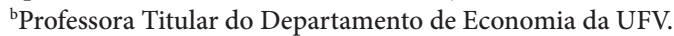

Artigo recebido em 11/08/2015 e aceito para publicação em 10/04/2017.

RESUMO: Objetiva-se analisar a evolução do fluxo migratório chinês, focando na piora da distribuição de renda, na concentração dos investimentos e no planejamento para o desenvolvimento do interior da China, utilizando como suporte teórico os pensadores clássicos do desenvolvimento. Pode-se verificar que as províncias com maiores investimentos são as mais procuradas pelos migrantes, que o fazem em busca de melhores oportunidades. A concentração da urbanização na região costeira e as desigualdades regionais na China poderão ser amenizadas por meio de um desenvolvimento regional focado nas províncias menos favorecidas, fazendo com que os trabalhadores busquem oportunidades em suas próprias províncias.

PALAVRAS-CHAVE: China; migração; planejamento regional; concentração dos investimentos; Hukou.

CLASSIFICAÇÃO JEL: O15; O18; R23; R58; R38.

Correspondência para: Frederick Fagundes Alves

Contato: frederick.alves@ufv.br 


\title{
SOCIOECONOMIC DISPARITY AND CHINESE MIGRATION FLOW: INTERPRETATION OF CONTEMPORARY EVENTS ACCORDING TO CLASSICS OF DEVELOPMENT
}

\begin{abstract}
This research aims to analyze the evolution of Chinese migration, focusing on the worsening distribution of income, the concentration of investments and planning for the development of inland China, being grounded, in most cases, by the classical thinkers of development. It could be seen that provinces with larger investments are the most sought after by migrants who are in the search of better opportunities. The concentration of urbanization in the coastal region and regional inequalities in China may be mitigated through a regional development focused on disadvantaged provinces, causing workers seek opportunities in their own provinces.
\end{abstract}

KEYWORDS: China; migration; regional planning; concentration of investments; Hukou. 


\section{INTRODUÇÃO}

O principal objetivo dessa pesquisa é analisar o fluxo migratório chinês a partir da interpretação de autores clássicos do desenvolvimento econômico, mais especificamente, Lewis, Rosenstein-Rodan e Kuznets. Com base nesses teóricos pretende-se estudar a evolução do processo migratório chinês, passando pela abertura econômica até a atualidade; e a evolução da concentração de renda, dos níveis de escolaridade, dos salários e dos níveis de emprego.

Basicamente uma nação rural por muitos séculos, a China começou a se industrializar rapidamente a partir de 1978. Com o progresso industrial, o campo veio sendo abandonado, e grande parte dos que permanecem no meio rural hoje são idosos que sempre viveram da agricultura. Os mais jovens, atraídos pelas possibilidades que os centros urbanos possivelmente podem oferecer, abandonam o campo em busca de novas oportunidades nas grandes cidades chinesas.

Além do fascínio que as cidades exercem sobre os chineses mais jovens, há ainda o problema da falta de atualização da prática agrícola no campo. Outro grave problema é a grande disparidade de renda entre os setores rural e urbano, que está associada ao êxodo rural, apesar das proibições do governo chinês com as normas do sistema hukou. O resultado foi o surgimento de milhares de trabalhadores em situação de clandestinidade em seu próprio país.

O sistema de residência hukou, criado em 1958 pelo regime de Mao Zedong ${ }^{1}$, parece ser uma das principais causas da enorme diferença econômica entre população urbana e rural na China. Esse sistema procura impedir que os chineses se mudem para outras localidades do país, dificultando a saída de quem nasceu e foi registrado em determinada região. Impede também que os migrantes rurais acessem todos os benefícios dos residentes urbanos, como seguridade social, educação, acesso à saúde pública, dentre outros benefícios. Segundo Wen (2002) e Ouriques e Andrade (2009), as políticas de industrialização do país privilegiavam os residentes dos grandes centros, pois essas regiões eram propensas ao crescimento e ao desenvolvimento, e desfavorecia aqueles que viviam no campo ou no interior do país.

Os camponeses migrantes iam para as cidades de forma ilegal e se submetiam a longas jornadas de trabalhos com baixos salários. Ao tentar fugir da pobreza rural, trocavam o campo, com pouca porção de terras aráveis, por péssimas ou até mesmo subumanas condições de trabalho nas cidades. Apesar disso, ainda há grande volume de migrantes rumo às grandes cidades, visto que a renda dos trabalhadores urbanos é significativa quando comparada à renda dos camponeses.

\footnotetext{
1 Houve nos últimos anos uma mudança no sistema de romanização utilizado pela China. O novo sistema,
} chamado Pinyin, adota Zedong ao invés de Tsé-Tung. Para mais detalhes, ver em Fairbank e Goldman (2006). 
Grande parte dos acontecimentos que ocorrem na China, atualmente, pode ainda ser explicada pelas teorias dos pensadores clássicos do desenvolvimento. Tais fatos envolvem problemas como a concentração do excedente de mão de obra de um país superpopuloso, considerado por Lewis (1969) como oferta de mão de obra "ilimitada", em uma região mais industrializada. Essas regiões, por serem mais dinâmicas, atraem um grande fluxo populacional em busca de melhores salários.

De acordo com os pensadores, tal situação pressiona cada vez mais para que o salário dos trabalhadores menos qualificados se fixe em um nível de subsistência. $\mathrm{Na}$ tentativa de amenizar tais problemas, Rosentein-Rodan (1961) sugere que um grande impulso em investimento deve ser realizado para que haja um desenvolvimento mais sólido. Porém, esse investimento deve ser dosado e direcionado para as regiões menos favorecidas com o intuito de reduzir as desigualdades.

No tema proposto, apesar da ampla discussão sobre os processos migratórios na China, há pouco consenso quanto às políticas que devem ser adotadas pelo governo chinês para o controle da concentração de renda verificada nas últimas décadas e maior desenvolvimento de regiões negligenciadas pelo poder público. Autores como Ouriques e Andrade (2009) e Wen (2002) discutem as dificuldades da mobilidade social, acarretadas pela evolução, ao longo do tempo, do sistema hukou, e a flexibilização desse sistema. Porém, Wen (2002) salienta, ainda, que essa política é perigosa e precisa de medidas de regulamentação para não incorrer em sérios problemas sociais, de saúde e miséria. $\mathrm{O}$ trabalho de Zhang e Song (2003) também mostra que a excessiva migração pode criar sérios problemas de desemprego e pobreza devido à limitada capacidade de absorção de mão de obra pelas indústrias, sendo necessário maior controle.

Diferentemente, Lin e Chen $(2008,2011)$ focam no aumento da taxa de urbanização e em estratégias de desenvolvimento para a indústria intensiva em trabalho como forma de reduzir as disparidades de renda entre os meios urbano e rural. Tais estratégias fariam com que os trabalhadores/camponeses tivessem mais oportunidades de emprego nas cidades, ampliando a taxa de urbanização e reduzindo a desigualdade entre classes. Já Mullan, Grosjean e Kontoleon (2011) analisam se os arranjos fundiários rurais impactam os fluxos migratórios na China, e esclarecem que famílias que correm risco de expropriação da terra não migrarão para áreas urbanas a fim de não perderem o direito ao uso da terra. Por fim, Nabuco (2012) foca sua discussão nas relações e condições trabalhistas enfrentadas pelos migrantes vindos do campo.

Como contribuição, este trabalho procurará analisar a evolução do fluxo migratório na China, tendo como foco a causa da piora na distribuição de renda, a concentração dos investimentos realizados, utilizando como base o pensamento dos teóricos clássicos do desenvolvimento econômico. 
Tal pesquisa se justifica visto que, de acordo com dados do National Bureau of Statistics of China (2012), pela primeira vez, no fim do ano de 2011, a população urbana chinesa $(51,27 \%)$ ultrapassou a rural $(48,73 \%)$. Além disso, ao comparar a renda anual das famílias urbanas com o rendimento médio das famílias rurais, tem-se que, em 2011, as primeiras obtinham anualmente rendimento médio de US\$3.557,00, enquanto as famílias rurais viviam com rendimento de US\$1.138,00 por ano. Segundo Morais (2011) e Medeiros (2012), o país iniciou o século XXI com extraordinário desempenho econômico, com alto crescimento e com redução da pobreza, porém com piora na distribuição de renda e difícil acesso aos bens públicos.

Ainda segundo o National Bureau of Statistics of China (2012), em toda a China, para o ano de 2011, os investimentos em ativos fixos foram de aproximadamente US\$ 141,9 bilhões no setor agrícola, enquanto no setor de manufaturados ultrapassou US\$ 1,66 trilhão.

Para isso, este artigo está dividido em cinco seções, tendo como início esta introdução. A segunda seção mostra que apesar da constante evolução das teorias, os teóricos clássicos do desenvolvimentismo ainda conseguem explicar os recentes fatos ocorridos na China. Nessa seção é apresentada uma base teórica que será consolidada com os recentes acontecimentos de migração, desigualdade de renda, mercado de trabalho e distribuição dos investimentos, apresentados nas seções 3 e 4. Finalmente, na última seção apresentam-se as considerações finais deste trabalho.

\section{A INTERPRETAÇÃO DO DESENVOLVIMENTO SEGUNDO OS TEÓRICOS PIONEIROS DO DESENVOLVIMENTO}

O crescimento econômico de um país envolve aumento na produção per capita acompanhado frequentemente de um aumento populacional e, geralmente, de grandes mudanças nas instituições ou práticas socioeconômicas (KUZNETS, 1974). A partir da revolução industrial, as principais alterações estruturais ocorreram: na mudança da produção agrícola para a produção não agrícola com a industrialização; na distribuição da população entre o campo e a cidade por meio do processo de urbanização; e na relativa posição econômica de alguns grupos dentro de cada país por meio dos status dos empregos e diferentes níveis de renda per capita.

As variações nas mudanças econômicas do período anterior à industrialização foram, ao longo do tempo, minimizadas por certos fatores, dentre os quais se destacam a estabilidade do crescimento populacional; o aumento do progresso técnico na agricultura, que reduz a possibilidade de colheitas fracassadas; os melhoramentos nos transportes, que permitem a ampliação de mercados e fontes de suprimentos; o declí- 
nio na participação da agricultura no produto total; e o aumento da participação de outros setores (indústria e serviços), que sofrem menos alterações cíclicas, por não serem afetados diretamente por fatores exógenos como as condições climáticas.

No período pós-industrialização, o produto per capita no setor agrícola aumentou a taxas muito menores do que o produto per capita nos setores industrial e de serviços. A explicação para tal afirmação, segundo Kuznets (1974), está na baixa elasticidade da demanda por alimentos e produtos agrícolas e na alta elasticidade por bens de consumo duráveis e alguns serviços.

A oferta ilimitada de mão de obra nos países onde a população é tão numerosa em relação ao capital e recursos naturais foi ressaltada por Lewis (1969), de modo que a produtividade marginal do trabalho seria ínfima, nula ou até mesmo negativa. Assim, em países populosos, o indivíduo pode oferecer qualquer quantidade de trabalho que o salário se fixará no nível de subsistência. Ou seja, o desemprego estrutural ou disfarçado não ocorre somente no setor agrícola, mas se estende às demais atividades econômicas desses países subdesenvolvidos.

Com isso, pode-se perceber que um aumento substancial na produtividade do setor agrícola é condição para o aumento na produtividade global da economia. $\mathrm{O}$ aumento na produtividade geral, combinado com a baixa elasticidade-renda da demanda por produtos do setor agrícola, explica o notável declínio da participação do setor agrícola no total de trabalho e capital empregados. Por meio da redução do excedente de mão de obra nos setores, pode-se perceber a elevação da produtividade e, com isso, um aumento da renda dos trabalhadores.

Com mais mudanças estruturais nas instituições ou práticas socioeconômicas, acompanhadas de um forte crescimento econômico, e, portanto, mobilidade interna significativamente maior, é provável que haja maiores mudanças nas rendas dos trabalhadores. Uma vez que haja redução do excedente de mão de obra agrícola, isso poderá levar a ganhos de produtividade nesse setor, com consequente aumento nos salários da mão de obra remanescente. Se os aumentos salariais ocorrerem de maneira sustentada, estes impactarão de forma positiva no produto final da economia, elevando a renda per capita e gerando crescimento econômico. Com isso, diferentes e sustentados aumentos na renda per capita são características fundamentais do crescimento econômico (KUZNETS, 1974).

Assim como Kuznets (1974), Lewis (1968) argumenta que, normalmente nos estágios iniciais de desenvolvimento, quando se está acelerando a taxa de crescimento econômico, a distribuição de renda torna-se mais desequilibrada, e, nos estágios posteriores, a distribuição estabiliza e em seguida tende a ser menos desigual. Tal distribuição torna-se mais desigual nos estágios iniciais porque a aceleração da taxa de crescimento cria uma escassez aguda dos fatores de produção. Os lucros aumentam, e uma 
vez que o setor não agrícola está crescendo mais rápido do que o agrícola, a parcela relativa dos lucros na renda nacional crescerá, ainda que a parcela relativa dos lucros no setor não agrícola permaneça constante. Acelera-se a procura por mão de obra qualificada e técnicos, e assim crescem os rendimentos da classe média. Pelo mesmo motivo, elevam-se os salários dos operários qualificados, comparados aos dos operários não qualificados.

Ainda seguindo os pensamentos de Kuznets (1974), as oscilações da distribuição de renda, em um período mais curto, podem ser analisadas como consequência, ao menos em parte, dos fatores envolvidos no crescimento econômico. Dessa forma, se a agricultura domina uma economia, a renda de determinada família envolvida diretamente com a produção rural poderá estar sujeita às falhas ou sucessos na colheita, enquanto nos países industrializados as flutuações da atividade econômica poderão dominar os movimentos da renda em curto prazo, tornando a produção menos vulnerável e mais bem planejada, o que refletirá em menor variação da renda familiar.

Assim, a distribuição de renda por classes está sujeita a muitos fatores, sendo alguns deles responsáveis por uma desigualdade menor, outros por uma desigualdade mais ampla. Então, nos primeiros estágios do crescimento econômico, parece realista supor que ocorreu uma ampliação da desigualdade na distribuição da renda total por classes devido a um rápido crescimento do setor não agrícola e uma desigualdade ainda maior dentro dele.

De acordo com o pensamento de Lewis (1969), o desenvolvimento econômico de países atrasados promove uma distribuição de renda em benefício da classe poupadora. Com isso, as classes mais ricas se apropriam integralmente do excedente, o que fará com que sua participação na renda nacional cresça, enquanto os trabalhadores permanecem estagnados com salários reais constantes. Em outras palavras, todo o potencial de poupança ou de investimento das economias subdesenvolvidas se concentrará nas mãos das classes mais ricas.

À procura de aumentos da renda, muitos abandonam o campo e migram para as cidades, contribuindo assim para o aumento da formação de grupos com renda inferior. Isto, combinado com um longo período de treinamento e qualificação da mão de obra da população urbana preexistente, pode ter contribuído para ampliar ainda mais a desigualdade.

Consequentemente, um considerável fluxo migratório entre regiões e deslocamentos ocupacionais por gerações são necessários para tentar ajustar a oferta de trabalho à demanda, com mudanças estruturais e deslocamento. Essas mobilidades populacionais, das quais a urbanização é parte importante, afetam as condições de vida e de consumo, os meios para adaptar as pessoas a seus papeis na economia e as instituições de transmissão de experiência de uma geração para outra. 
A importância dos salários para determinar fluxos migratórios é enfatizada por Lewis $(1960,1965)$.

They [wages] are important both positively and negatively; positively in that superior wages do attract, and negatively in that superior wages are needed to offset unpleasant conditions of labour - work that is dirty or hot or monotonous. (LEWIS, 1965 , p. 83)

As remunerações superiores atraem pessoas, mas devem ser suficientes para compensar as condições desagradáveis de trabalho nos grandes centros. Com o aumento populacional inflando os grandes centros, pioram as condições de vida, diminui a rentabilidade marginal dos recursos, sobem os alugueis por falta de oferta suficiente, aumenta o custo de abastecer a cidade com alimentos, água e outras utilidades provenientes de distâncias cada vez maiores, eleva-se o custo dos transportes urbanos e congestionam-se as ruas e outros serviços. Portanto, segundo Lewis (1968), eleva-se o custo de vida, o que reflete nos salários. Os camponeses encaminham-se para as cidades em busca de melhores remunerações e trabalho ocasional, dessa forma, o desemprego disfarçado ou estrutural, como chamado por Lewis (1969) e Rosenstein-Rodan (1961), transforma-se em desemprego aberto. Obviamente há ganhos devido à aglomeração populacional e industrial nos grandes centros, como, por exemplo, um ambiente mais favorável para a instalação de empresas, incentivado pelas externalidades positivas geradas pela concentração das atividades econômicas, da redução dos custos logísticos e do surgimento de atividades complementares. Para aqueles indivíduos que migram em busca de novas oportunidades, devem-se destacar os ganhos de conhecimento em novas técnicas produtivas e a difusão do conhecimento.

As pessoas chegam aos centros procurando trabalho, e quer o encontrem, quer não, permanecem em virtude das atrações que a cidade oferece. Ao entrar em contato com o meio urbano, os camponeses irão adquirir os novos gostos sociais e hábitos de consumo que aumentam a pressão salarial. Além disso, a sindicalização, já presente nas cidades, influencia para que esses salários se elevem, dado o nível de politização do trabalhador urbano (LEWIS, 1968). Entretanto, como boa parte da população camponesa está limitada ao nível de subsistência, basta um pequeno aumento no patamar salarial para justificar o êxodo rural. Nesse caso, a oferta ilimitada de mão de obra ajuda a manter os salários urbanos em níveis muito baixos (LEWIS, 1969). Contudo, a pressão é feita no sentido de salários mais altos, o que, por sua vez, atrai ainda mais gente, num processo cumulativo. Quanto maior a diferenciação entre os salários urbanos e os rendimentos rurais, maior será o afluxo. 
Ao incentivar a transferência de mão de obra do setor primário para a indústria, é necessário que esta última pague salários maiores, não apenas para tornar-se uma promessa de melhoria do nível de vida, como também para compensar a elevação do custo de se viver nas cidades. A industrialização, assim, tende a elevar o nível de renda do país. Contudo, já não é mais possível obter rendimentos apenas com transferência de mão de obra da agricultura para a indústria, uma vez que o setor secundário não tem a capacidade de absorver a oferta ilimitada de mão de obra.

O conceito do grande impulso (big push) de Rosenstein-Rodan (1961) defende que há um nível mínimo de recursos que deve ser investido para que um programa de desenvolvimento tenha alguma probabilidade de êxito. Porém, a distribuição do investimento ocorre necessariamente em um mercado imperfeito, gerando, assim, riscos e imperfeições maiores para os países subdesenvolvidos.

Para que seja feito o mínimo de investimento, é necessário um alto volume de poupança, o que é difícil de obter em países subdesenvolvidos e de baixa renda. Um grande impulso parece ser necessário para ultrapassar os obstáculos econômicos e alcançar o desenvolvimento. Pequenos e isolados esforços para realizar os investimentos talvez nada signifiquem como impulso para gerar crescimento. Com isso, o governo deverá utilizar suas “armas” políticas para incentivar o investimento, que deverá ser dosado e direcionado, para planejar o desenvolvimento.

Segundo Lewis (1968), existem algumas regiões num país, não necessariamente as mais ricas, que se desenvolvem mais rápido que outras. É comum que esse desenvolvimento se deva a erros de política econômica². De acordo com Kuznets (1974), a existência de diferenças entre as regiões fornece tanto indução quanto oportunidade para o crescimento das áreas atrasadas.

Porém, as forças que levam ao crescimento das grandes cidades continuam, enquanto os incentivos para o desenvolvimento do interior são abafados. Existem pressões urbanas através dos sindicatos para não redução dos salários e também redução

2 Tendo como exemplo o caso chinês, pode-se destacar que a partir de 1949, com Mao Zedong e o Partido Comunista no poder, houve a implementação de medidas políticas e econômicas com foco em um rápido e intenso processo de industrialização. No entanto, concomitantemente à promoção da igualdade de renda nacional e à elevação dos indicadores de saúde e educação, houve estagnação da produtividade agrícola, paralisando o processo de desenvolvimento do campo. Apesar das falhas ocorridas no período liderado por Mao Zedong, segundo análise de muitos estudiosos, este deixa como legado para o governo de Deng Xiaoping (1978 a 1992) bons indicadores de saúde e educação, indústria de base crescente, produção geral também crescente e ampla adoção de fertilizantes e insumos agrícolas. A China de Deng Xiaoping, por sua vez, através de novas reestruturações políticas e econômicas de abertura comercial, eleva ainda mais o nível de crescimento chinês, apesar do aumento da desigualdade entre os meios rural e urbano. Alguns dados serão apresentados nas seções 3 e 4 para maiores esclarecimentos sobre as políticas adotadas. 
dos incentivos para que as indústrias sejam localizadas fora da zona de congestionamento. Assim, a população da grande cidade ou região cresce muito acima de seu tamanho econômico adequado, às custas de outras regiões onde, do ponto de vista econômico, o investimento de recursos seria mais produtivo.

No caso de uma grande empresa migrar de uma cidade para outra, vários serão os efeitos enfrentados tanto pela cidade de onde saiu quanto pela cidade de destino. A cidade que essa empresa abandonou sofre uma redução do mercado, levando algumas empresas menores a também se mudarem, o que gera um efeito multiplicador. As indústrias preferem estar próximas umas das outras, onde possam contar com boas instalações e se beneficiar da existência de indústrias básicas e do conhecimento adquirido via outras indústrias. Já na cidade para a qual a empresa se transferiu há um movimento ascendente cumulativo.

Ao se preocupar em desenvolver determinada região, o melhor a se fazer é proceder por meios de incentivos, como fornecer os serviços básicos que as indústrias necessitam e subsidiar os serviços que forem necessários. Mas, mesmo quando são realizados os possíveis esforços para reduzir custos para a empresa, esta pode não se deslocar de determinada área devido a algum inconveniente na região que não a favoreceria (LEWIS, 1960).

Com isso, segundo Kuznets (1974), muitos questionamentos surgem a respeito da localização das novas indústrias: se estas devem sedispersar por todo o interior do país, proporcionando oportunidades extras de emprego para as famílias dos trabalhadores rurais, ou se devem se concentrar apenas nas grandes cidades, com centralização de mão de obra. Há algumas indústrias que, possivelmente, sobreviveriam dispersas pelo interior do país, porém não são muito numerosas. Para isso, a região escolhida necessita de um bom planejamento direcionado às indústrias selecionadas de subsídios para sua instalação, de estrutura básica para os trabalhadores e suas famílias, dentre outros fatores.

Portanto, se as pequenas cidades do interior, intensivas em mão de obra agrícola, receberem parcela adequada dos gastos de desenvolvimento, migrar para as grandes cidades já não seria mais tão atraente. Nesse sentido, com a devida atenção dada ao desenvolvimento de regiões esquecidas, é mais provável que as pessoas se encaminhem para cidades menores, próximas de onde vivem, se melhorias ocorrerem nessas localidades.

Como forma de demonstrar que a teoria clássica do desenvolvimento econômico ainda consegue explicar grande parte dos eventos que acontecem na China, as próximas seções trazem fatos que corroboram a teoria apresentada. 


\section{MERCADO DE TRABALHO, SALÁRIO E MIGRAÇÃO NA CHINA}

\subsection{SISTEMA DE RESIDÊNCIA E MIGRAÇÃO NA CHINA}

O sistema de residência ( $h u k o u$ ) é utilizado pelo governo como mecanismo de controle migratório e social, controlando a velocidade da urbanização, os limites populacionais e a oferta de mão de obra. De acordo com o National Bureau of Statistics of China (2014) e Ouriques e Andrade (2009), esse sistema foi criado em 1951, e legitimado de fato em 1958, com os objetivos de: (i) desencorajar a movimentação dos habitantes do campo para as cidades; (ii) ajudar o governo a alocar a força de trabalho entre os municípios e províncias; e (iii) controlar a movimentação dos inimigos do governo, como os membros do Kuomingtang.

Segundo Zhang e Song (2003) era mais simples entrar no "paraíso" do que conseguir um registro urbano. Alguns requisitos necessários para conseguir o registro de residência urbano são: (i) ter alto nível de escolaridade; (ii) ser do partido comunista; (iii) ou entrar para o Exército de Libertação Popular. Porém, nem o partido comunista e nem o exército fazem recrutamentos na zona rural e, quanto ao nível de escolaridade, os chineses jovens vão clandestinamente para as cidades grandes, perdendo os direitos de frequentar a escola pública (dentre outros), e, com isso, interrompem seus estudos, não conseguindo, assim, escolaridade suficiente.

Com o início da flexibilização do hukou, em meados dos anos 1980, os migrantes passaram a se tornar numerosos nas cidades. Desde então, iniciaram-se os fluxos migratórios das zonas rurais para as cidades povoadas com Townsand Village Enterprises $(\text { TVEs })^{3}$, e a migração de longas distâncias pela busca de empregos nas fábricas da zona costeira, canteiros de obras nas cidades e para o mercado informal. Aos poucos, esse processo migratório expandiu a saída de mão de obra do setor de subsistência para o setor capitalista em formação. Esse fato corrobora o pensamento de Kuznets (1977), segundo o qualo simples deslocamento da força de trabalho do setor agrícola para os setores industrial e de serviços aumentaria a participação global de empregados com salários mensais entre os trabalhadores. Essa tendência ocorreria mediante a busca por empregos formais.

Com o processo de flexibilização da migração, em 1983, veio a concessão de registros emitidos temporariamente, pela qual a migração foi permitida por tempo determinado, porém, sem direito de acesso aos benefícios sociais e aos subsídios urbanos.

\footnotetext{
3 As TVEs, anteriormente denominadas “Commune and Brigade Enterprises” (1958-1960), são empresas estatais instaladas nos municípios do interior com função de industrializar algumas regiões chinesas.
} 
Aqueles que migrassem clandestinamente estariam sujeitos à fiscalização policial, além de não conseguirem empregos registrados nas empresas.

Como salienta Morais (2011), nas maiores cidades (Shanghai e Beijing), além do diploma de alguma universidade reconhecida, é preciso ter emprego fixo na cidade para tentar a mudança do registro de residência, e apenas aqueles com título de doutor podem escolher ter registro urbano sem necessidade de emprego fixo. Em grande parte das cidades, a compra de um imóvel de alto padrão também pode qualificar o indivíduo para mudança de hukou rural para urbano. Além disso, as grandes empresas têm cotas para atrair os migrantes mais qualificados - são mecanismos de privilégios para aqueles mais estudados e ricos. Lewis (1969) salienta que a oferta ilimitada de mão de obra se aplica somente ao trabalho não qualificado. Diferentemente, o trabalho qualificado tem algumas regalias por parte dos governos e das empresas para que não se cause um estrangulamento temporário no crescimento ${ }^{4}$.

Já aqueles com baixo nível educacional e com pouco poder aquisitivo vão entrar no nível mais baixo do mercado de trabalho urbano chinês, além de ter acesso precário aos serviços sociais nas cidades. Os migrantes desqualificados não só são deixados de lado da estrutura de benefícios sociais das cidades como também da sociedade desses lugares, principalmente pela extensa carga horária das fábricas e da falta de documentos.

Com o tempo, a migração se tornou mais organizada pelos governos provinciais e pequenos vilarejos. Os departamentos de trabalho passaram a organizar grupos de migrantes e agenciá-los na construção civil, em fábricas ou como empregados domésticos nas províncias de destino. Algumas províncias estabeleceram escritórios para organizar com mais seriedade a força de trabalho que chegava. Esse mecanismo acabou por se tornar rapidamente uma das formas mais simples para que os trabalhadores migrassem com algum tipo de garantia de emprego nas cidades (NABUCO, 2012).

Da virada do século em diante, um fluxo cada vez maior da segunda geração de migrantes começa a se dirigir para as grandes cidades, o que eleva ainda mais a população da região leste. Esses migrantes não foram criados trabalhando na agricultura, e abandonaram os estudos em torno dos 16 anos em busca de novas oportunidades nas fábricas ou canteiros de obras.

4 Em qualquer momento pode ocorrer escassez de mão de obra qualificada de qualquer tipo, e isso pode ser o gargalo do crescimento, assim como o capital e a terra. Porém, uma vez que se disponha de capital para o desenvolvimento, os capitalistas e o governo proverão de imediato as facilidades para o treinamento de maior número de trabalhadores qualificados (LEWIS, 1969). 
Com relação às disparidades da renda por região e entre rural e urbano, pode-sever na Tabela 1 que a renda per capita urbana da região mais dinâmica (leste) é cerca de 3,7 vezes maior do que a renda rural per capita da região menos dinâmica (oeste). Além disso, as rendas rurais per capita das regiões costeiras (leste e nordeste) superam a renda rural per capita da região menos dinâmica (oeste) em 2011.

Tabela 1 - Renda média per capita por região da China, 2011 (em yuan)

\begin{tabular}{lcccc}
\hline & Região Leste & Região Central & Região Oeste & Região Nordeste \\
\hline Renda Urbana & $29.226,04$ & $19.868,19$ & $19.868,03$ & $20.163,20$ \\
Renda Rural & $12.495,33$ & $8.790,86$ & $7.854,70$ & $13.996,22$ \\
\hline
\end{tabular}

Fonte: Elaboração própria com base em dados do National Bureau of Statistics of China (2012).

Lewis $(1960,1969)$ observa que pode haver diferenças entre os salários nos setores capitalistas e de subsistência, e que tais diferenças estão em torno de 30\%, podendo ser explicadas pelo custo de se viver em cidades congestionadas, com altos preços de alugueis e transporte. Tais diferenças salariais se encontram mesmo em economias mais adiantadas. Porém, como pode ser visto na Tabela 1 , na China essa desigualdade salarial entre os setores ultrapassa os $30 \%$ previstos por Lewis.

No início do processo de reformas, a maioria dos migrantes sem registro se constituía de homens, jovens e com jornadas de trabalho acima das oito horas diárias permitidas por lei. Baseado nos dados do CHIP Project (ICPRS, 2002), cerca de $81 \%$ dos migrantes trabalhavam os sete dias da semana, enquanto a lei define apenas cinco dias. Apenas um quarto desses migrantes sem registro tem jornada de trabalho de oito horas, enquanto 34\% cumpriam jornadas de 9 a 10 horas diárias, e 25\% com carga horária de trabalho entre 11 e 12 horas.

Como reporta Morais (2011), a maioria dos jovens migrantes vive nos precários dormitórios das fábricas e tem como objetivo juntar dinheiro o mais rápido possível para enviá-lo aos familiares, fazer um curso técnico ou investi-lo em algum negócio na cidade ou no lugar de origem. A rotatividade nas empresas é bastante alta, e quando chegam aos 25 anos, esses migrantes são considerados "velhos" para continuar nas linhas de montagem, e se não conseguirem algo melhor na hierarquia das empresas, partem para o setor de serviços ou mercado informal.

\subsection{MERCADO DE TRABALHO E REMUNERAÇÃO DOS TRABALHADORES}

Segundo Lewis (1969), em economias com oferta "ilimitada" de mão de obra a um salário de subsistência, a remuneração dos trabalhadores, inclusive do setor formal, está 
relacionada ao nível de remuneração dos trabalhadores do setor de subsistência. Em economias nas quais grande parte da população vive no campo, a remuneração mínima pelo trabalho é a produção média desses camponeses. Nesse caso, o camponês não abandonaria a terra da família em troca de um emprego na cidade se a remuneração na cidade não fosse capaz de suprir o que ele já consome se permanecer em sua terra.

Visto que o salário do setor capitalista depende do salário no setor de subsistência, Lewis (1969) argumenta que os capitalistas teriam interesse em manter a baixa produtividade do setor de subsistência. Caso essa produtividade viesse a aumentar, elevaria os salários reais no setor capitalista e reduziria o excedente e, consequentemente, a taxa de acumulação do capital. Contudo, o salário mais baixo de toda economia seria a remuneração do trabalhador rural ligado à agricultura de base, voltada unicamente para o mercado interno.

Até meados da década de 1980, a China vivenciava um grau relevante de equidade salarial, pleno emprego e imobilidade dos trabalhadores, em que era inaplicável a análise de Lewis. O estado administrava os salários, responsabilizava-se por encontrar emprego vitalício e as empresas estatais ofereciam benefícios e bens públicos não comercializáveis aos seus dependentes. Entre 1978 e 1986, de acordo com Medeiros (2012), os empregos no setor produtivo estatal e nas TVEs totalizavam cerca de 66,6\% do emprego total, em que as TVEs empregavam cerca de 95 milhões de pessoas.

Algumas reformas, com intuito de descentralizar a alocação dos trabalhadores, iniciaram de maneira gradual na década de 1980. Em 1986, os novos trabalhadores estatais passaram a assinar contratos de trabalho de curta duração (cinco anos), que poderiam ou não ser renovados ao fim do período, levando a população mais jovem a conviver com a ideia de desemprego. No início da década de 1990, começam a surgir casos de jovens desempregados e/ou que precisaram mudar de emprego. Porém, o desemprego aberto, considerado por Lewis, estava sendo amenizado em parte pelo controle da migração.

Com essas mudanças institucionais no mercado de trabalho chinês, e com as privatizações e demissões em massa no setor público nos anos 1990, houve o crescimento expressivo do emprego informal nas regiões urbanas. Essa informalidade do emprego foi acompanhada do fluxo de migrantes para as grandes cidades, como pode ser visto na Figura 1, que mostra a densidade populacional nas principais cidades e distritos chineses. 
Figura 1 - Densidade populacional (habitantes $/ \mathrm{km}^{2}$ ) nas cidades e distritos chineses, 1990-2011

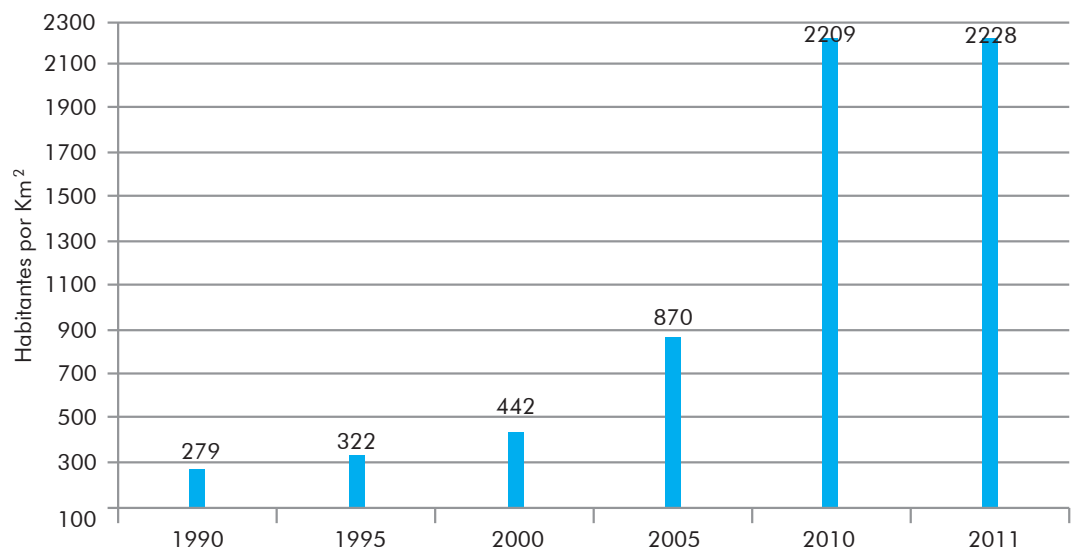

Fonte: Elaboração própria com base em dados do National Bureau of Statistics of China (2012).

Grande parte dos desempregados na China no fim da década de 1990 era de trabalhadores com registro urbano. Enquanto o número de empresas estatais estava sendo reduzido, o número de empresas privadas, que contratavam mão de obra migrante, crescia cada vez mais nas grandes cidades e também nas regiões interioranas com as TVEs (NABUCO, 2012).

Ao fim dos anos 1990, a China se caracterizava cada vez mais como um país subdesenvolvido e superpopuloso, como uma economia com oferta "ilimitada" de mão de obra. A partir desse período, a análise de Lewis pode ser aplicada à economia chinesa devido à grande parcela de emprego informal, de baixa produtividade e baixos salários, de um lado, confrontada com setores capitalistas de alta produtividade e salários mais elevados, de outro.

Até o início dos anos 1990, a desigualdade nas remunerações do mercado de trabalho urbano chinês era razoável. É a partir da segunda metade da década de 1990 que a dispersão salarial começa a aumentar. De acordo com Morais (2011), em 1988 o coeficiente de Gini para a remuneração do trabalhador urbano era de 0,23; já em 1995 passou para 0,30, considerado um nível moderado. De 1995 em diante, a dispersão salarial aumenta ainda mais e o Gini passa para 0,36 em 2007.

A parcela dos salários na renda total caiu devido à piora relativa das remunerações dos trabalhadores rurais, do setor informal e do migrante sem registro, portanto, devido à queda relativa dos salários no setor de subsistência, como exposto na teoria de Lewis. Os salários reais dos migrantes parecem ter ficado estagnados até os anos 2000, apresentando altas de $4 \%$ e $5 \%$ na primeira metade da década de 2000, o que representa menos da metade do ritmo de crescimento dos salários dos moradores com registro urbano. 
Algumas pesquisas paralelas às estatais estimam que esses migrantes representavam, em 2005, 46\% da força de trabalho urbana, 53\% em 2010, e que deverá chegar a $68 \%$ até 2020 . A remuneração média de um trabalhador migrante sem registro urbano, segundo pesquisa intutilada China Household Income Project (ICPRS, 2002), era de menos da metade daquela conseguida por um trabalhador com registro urbano.

A produção e o mercado de trabalho chinês foram afetados com a crise internacional, iniciada em 2007, que também gerou um grande impacto em muitos países do mundo. A elevação dos preços de diversas matérias-primas, a valorização do Yuan e a queda da demanda por produtos chineses levaram a mudanças abruptas na indústria chinesa. Essas mudanças reduziram a produção, levando milhões de trabalhadores migrantes de volta ao campo.

Apesar dos cálculos da taxa de desemprego não serem exatos, estima-se que o desemprego tenha afetado 23 milhões de trabalhadores migrantes em 2009, cerca de $16,4 \%$ do total de migrantes. Essa taxa de desemprego é muito elevada quando comparada com as taxas de desemprego anteriores, que oscilavam entre $1 \%$ e $2 \%$ para os trabalhadores migrantes enquanto o desemprego daqueles com hukou urbano parece ter continuado estável (4,1\%) (NABUCO, 2012).

Ao retornar para o meio rural, os migrantes enfrentavam diversos problemas como a falta de experiência ou de completo desconhecimento das práticas agrícolas; pequenas porções de terra que muitas vezes estavam abandonadas ou sem condições de ocupação; e, muitas vezes, a terra destinada a estes não tinham acesso à água, insumos agrícolas e não era arável, consistindo nas principais razões para que muitos abandonassem o campo.

Com o auxílio de diversas iniciativas do governo e de pacotes de estímulo, a economia chinesa começa a dar sinais de recuperação em 2013. Em 2011, o PCC aprovou o $12^{\circ}$ Plano Quinquenal Chinês, que traça as diretrizes estratégicas que o país pretende seguir até 2015. Visto como o mais ousado pelos analistas, esse plano pretende se desligar do modelo de crescimento manufatureiro puxado por investimentos e exportações, e se voltará para um modelo baseado na expansão do consumo interno e ampliação dos serviços que dependerá de mais mão de obra. O modelo anterior impedia o mercado chinês de absorver a imensa mão de obra excedente no país (ROACH, 2011).

Essa mudança estratégica também tem iniciativas como elevação dos salários defasados, principalmente as remunerações rurais; reforma de política fiscal, para aumentar o poder de compra rural; e medidas para ampliar a propriedade fundiária e aumentar a produtividade agrícola. Mas a maior promessa vem do relaxamento das restrições para mobilidade populacional e migração.

Segundo Morais (2011), os salários dos migrantes estariam subindo mais rapidamente, colocando suposto fim à era de mão de obra barata na China. Atualmente, a 
renda rural tem aumentado acima do registrado antes de 2004, devido aos subsídios dados aos camponeses, à abolição dos impostos sobre a agricultura e aos termos de trocas favoráveis à agricultura. Esses fatores podem explicar o recente aumento dos salários dos migrantes, dado o aumento na renda dos camponeses e a pressão exercida nos salários dos migrantes.

Lewis (1969) salienta que à medida que o excedente de mão de obra vai sendo esgotado, os salários começarão a subir acima do nível de subsistência. Porém, o país ainda é cercado por outros países que ainda possuem excedente de trabalho, e que haverá uma imigração desses países para aquele com elevação salarial. Esse processo de imigração terá como efeito o retorno das remunerações aos níveis mais baixos, iguais aos dos países vizinhos. No entanto, observa-se que esse fato, previsto por Lewis (1969), ainda não se aplica ao caso chinês, uma vez que este é um país superpopuloso no qual grande parte da mão de obra vive no nível de subsistência. Além disso, apesar da atual abertura ao capitalismo e à globalização mundial, a China possui algumas regras rígidas com relação ao controle migratório dentro e fora de suas fronteiras.

A próxima seção tem como objetivo ilustrar alguns dos aspectos já citados ao longo deste trabalho e que são relevantes para observar a migração entre províncias na China. Por meio de dados disponibilizados pelo governo chinês, foram elaboradas figuras para melhor entendimento da concentração dos investimentos e também de características ligadas aos migrantes.

\section{CONCENTRAÇÃO DOS INVESTIMENTOS E MIGRAÇÃO}

Como forma de discutir os fluxos migratórios e de investimentos na China, faz-se uso de mapas que melhor ilustram a situação chinesa a respeito do nível educacional da população migrante, dos investimentos realizados e dos fluxos migratórios pelas províncias e regiões chinesas ao longo do tempo.

Na Figura 2 estão dispostos os investimentos em agricultura realizados nos anos de 2000 e de 2011. Observa-se que esses investimentos estão concentrados com maior predominância na região leste tanto para o ano 2000 quanto para o de 2011. Em 2000, cerca de US\$ 25,32 milhões $^{5}$ foram investidos na agricultura da província de Hebei, enquanto, em 2011, os maiores investimentos foram realizados na província de Shandong, totalizando mais de US\$11,7 bilhões.

\footnotetext{
5 A conversão de yuan para dólar americano foi realizada por meiodo conversor de moedas do Banco Central do Brasil, considerando a última cotação do ano de 2000 e de 2011.
} 
No ano 2000, os menores investimentos na agricultura chinesa se concentraram nas regiões central e oeste. As províncias de Guizhou e Jiangxi totalizaram cerca de US\$ 240 mil e US\$ 480 mil em investimentos, respectivamente, enquanto nas províncias Jilin e Quinghai foram investidos US\$ 840 mil em cada. Nesse mesmo ano, os maiores investimentos em agricultura foram na província de Jiangsu (leste), que recebeu cerca de US\$11.760.000,00, e em Hebei, como destacado acima.

Os menores investimentos, realizados no ano de 2011, estão localizados nas províncias de Hainan e Tibet (cada uma com US\$ 387 milhões) e Shanghai (US\$297,6 milhões). Já no ano de 2011, os maiores níveis de investimento estavam em Shandong (leste), Henan (centro) e Heilongjang (centro), com mais de US\$ 11,7 bilhões, US\$ 11,5 bilhões e US\$10,49 bilhões, respectivamente, o que mostra maior diversificação das regiões investidas.

Figura 2 - Investimento agrícola por província em 2000 e 2011 (em 100 milhões) de dólares

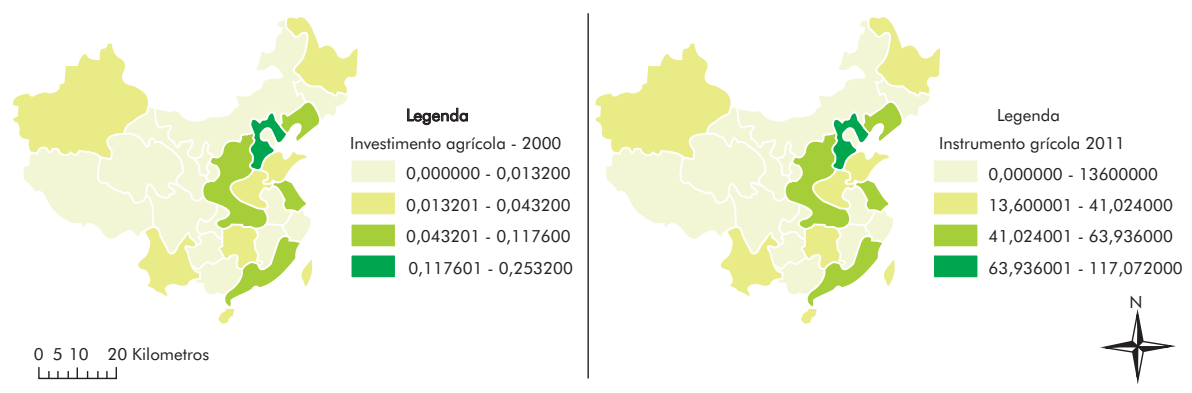

Fonte: Elaboração própria com base em dados do China Statistical Yearbook (2012).

A distribuição percentual dos investimentos em agricultura nas regiões leste, centro e oeste, em 2000, giraram em torno de 59\%, 26\% e 15\%, respectivamente, o que mostra a alta concentração desse tipo de investimento na região costeira do país. Já no ano de 2011, a distribuição percentual do investimento agrícola reduziu-se para 31\% na região leste, e elevou-se para $48 \%$ e $21 \%$ nas regiões central e oeste, respectivamente.

Como destacado acima, Lewis (1969) mostra que para manter os níveis salariais tendo o salário de subsistência como base, os capitalistas não terão grande interesse em elevar a produtividade no meio agrícola, e, com isso, os conhecimentos e os investimentos na agricultura. Dessa forma, esses capitalistas garantem maiores lucratividades e a elevação da taxa de acumulação do capital.

A Figura 3 mostra a concentração dos investimentos realizados em manufatura e construção nas províncias da China. Além de ter um dos menores investimentos agrícolas de 2011, a província de Tibet, na região oeste do país, também tem os menores 
investimentos em manufaturados e construção civil para os anos de 2000 e 2011, US\$ 360 mil e US\$1,05 bilhão, respectivamente. As províncias Ningxia (oeste) e Hainan (leste) também apresentaram investimento abaixo da média de suas regiões, respectivamente, US\$ 2,76 milhões e US\$ 4,44 milhões, em 2000.

Os maiores investimentos em manufaturados e construção civil no ano de 2000 foram cerca de US\$ 576,12 milhões, US\$ 514,8 milhões e US\$ 308,52 milhões, em três províncias da região leste, respectivamente, Jiangsu, Shandong e Hebei. Deve ser lembrado que, para esse mesmo ano, Jiangsu e Hebei tiveram os maiores investimentos na agricultura.

Figura 3 - Investimento em manufaturados e construção por província em 2000 e 2011 (em 100 milhões) de dólares

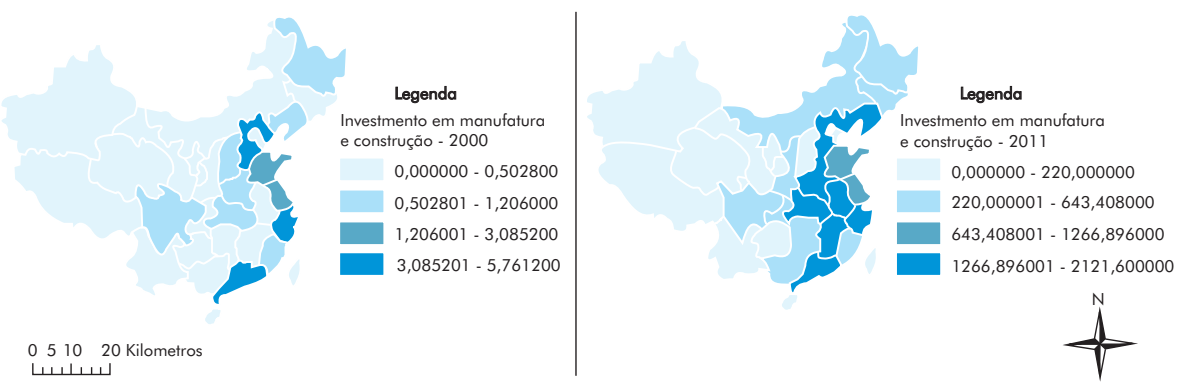

Fonte: Elaboração própria com base em dados do China Statistical Yearbook (2012).

Em 2011, Jiangsu e Shandong continuaram sendo as províncias com maiores investimentos em manufaturados e construção civil, com valores que totalizaram mais de um trilhão de yuanes. Em dólares, esses valores representam cerca de US\$212,16 bilhões para Jiangsu e US\$ 179,98 bilhões de investimentos em Shandong.

Ao comparar os investimentos médios para cada região no ano de 2000, nota-se que a região leste investiu em manufaturados e construção mais de oito vezes o valor investido na região oeste. Já em 2011, essa diferença de investimento regional reduziu-se para cerca de 3,4 vezes. Enquanto a região leste teve, em média, US\$ 74,4 bilhões de investimento em manufaturados e construção, as regiões central e oeste tiveram cerca de US\$ 64,8 bilhões e US\$21,76 bilhões, respectivamente.

À medida que o excedente capitalista é reinvestido a fim de criar novo capital, o setor capitalista se amplia, transferindo-se um maior número de indivíduos do setor de subsistência para o setor capitalista. O excedente torna-se, então, ainda maior, a formação de capital aumenta ainda mais e, assim, o processo continua até que o excedente de mão de obra sejareduzido (LEWIS, 1969). 
A Figura 4 apresenta o fluxo migratório, bastante intenso, existente de uma província para outra. Segundo dados do censo demográfico de 2010, cerca de 261 milhões de chineses deixaram seu local de origem (cidades, vilas, comunidades e províncias) e migraram para outras localidades. Deve-se salientar que, para melhor visualização, optou-se por apresentar somente a migração entre províncias, deixando de lado migrações de "curtas distâncias", como entre cidades, vilarejos e comunidades da mesma província.

\section{Figura 4 - Residência atual de migrantes com registro de residência de outras províncias, 2010}

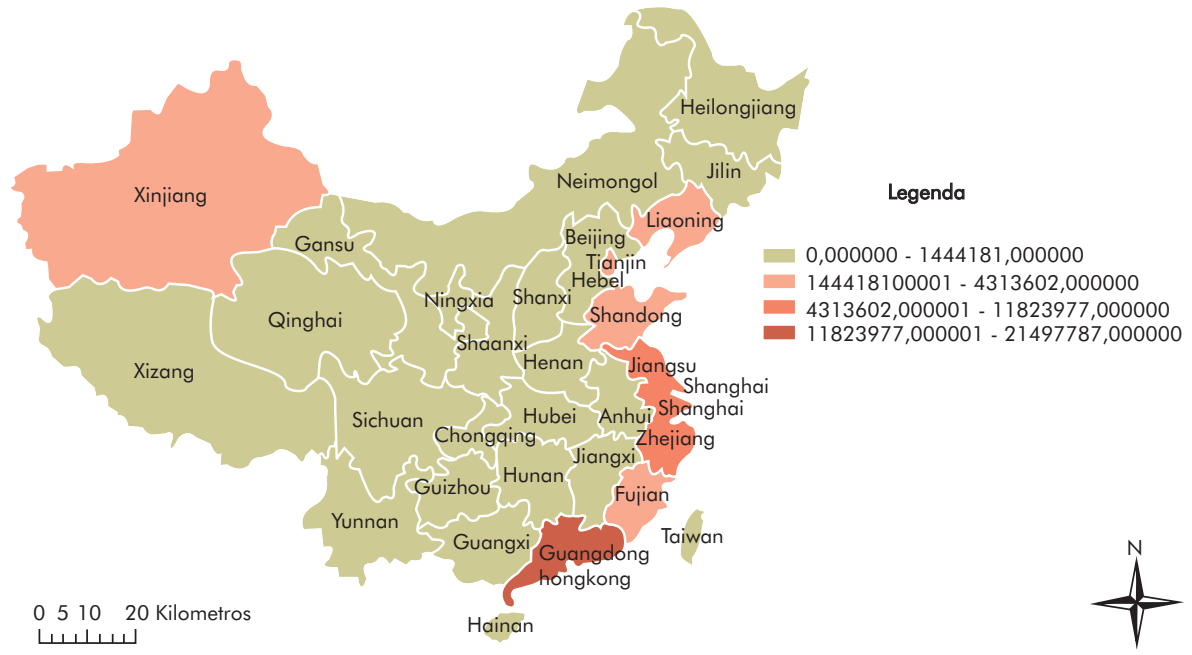

Fonte: Elaboração própria com base em dados do Censo Demográfico chinês de 2010.

Apesar de todas as melhorias ocorridas a com elevação dos níveis de investimentos por todo o país, a região costeira ainda continua atraindo o maior fluxo de migrantes em busca de diferentes oportunidades. As províncias que recebem o maior número de migrantes são: Guangdong, com cerca de 21,5 milhões; Shanghai, com 8.977.000; Jiangsu e a capital Beijing, com mais de sete milhões cada uma. Em comparação, Tibet (Xizang), Quinghai e Ningxia são os destinos menos procurados pelos migrantes, além de serem as províncias com os mais baixos níveis de investimentos em agricultura, manufaturados e construção de 2011.

Dentre as províncias da região oeste, Xinjiang se destaca ao receber mais de 1,7 milhão de migrantes. O principal motivo desse fluxo migratório é que o governo local fornece subsídios à população visando aumentar a proporção de chineses da etnia Han em relação à população local de etnia turca e mulçumana. Além disso, por ser grande 
produtora de algodão, petróleo e gás natural, a província tem maior geração de empregos e aumento dos investimentos ao longo do tempo.

Ainda na Figura 4 pode-se notar, segundo o pensamento de Lewis (1969), que existem algumas "ilhas" de emprego capitalista cercado de um "mar" de trabalhadores no nível de subsistência. A aglomeração em algumas regiões é típica de países que se encontram na primeira fase do desenvolvimento, o que ainda se aplica à China. Verifica-se a existência de algumas cidades modernas (Beijing, Shanghai, Hong Kong etc.), com a melhor arquitetura, abastecimento de água, boas comunicações e outras coisas semelhantes, para as quais convergem indivíduos de outras cidades e vilas que destoam daquele ambiente mais moderno (LEWIS, 1969).

Na Tabela 2 são considerados todos os destinos de migração, cidades, províncias, vilarejos, distritos etc., além de serem discriminadas as razões que levaramà migração. De acordo com os dados expostos abaixo, tem-se que o número de homens migrantes é superior ao número de mulheres migrantes em cerca de 13 milhões, porém, o número de mulheres com idade em torno de 20 a 24 anos que migram supera o de homens dessa mesma faixa etária.

Segundo o censo demográfico chinês de 2010, o principal motivo da migração foram novos negócios e empregos, com mais de 117 milhões de migrantes, seguido do número de pessoas que migram por serem dependentes (36,9 milhões). Os que mudam de seu local de origem para estudar estão em torno de 29,7 milhões, e se deslocam com maior intensidade na faixa etária de 15 a 19 anos. De todos esses migrantes, apenas 1.868.223 conseguiram transferência do hukou, ou seja, outro registro constando o novo local de moradia.

Grande parte dessas pessoas migra em busca de oportunidades de trabalho nas indústrias e nas grandes empresas. Segundo Lewis (1969), à medida que se dispõe de mais capital (expansão do setor capitalista), pode-se levar mais trabalhadores do setor de subsistência para o capitalista, aumentando o produto per capita enquanto se passa de um setor para o outro. 
Tabela 2 - População com registro familiar de outra província, cidade ou distrito, por idade, sexo e razão de migração, 2010

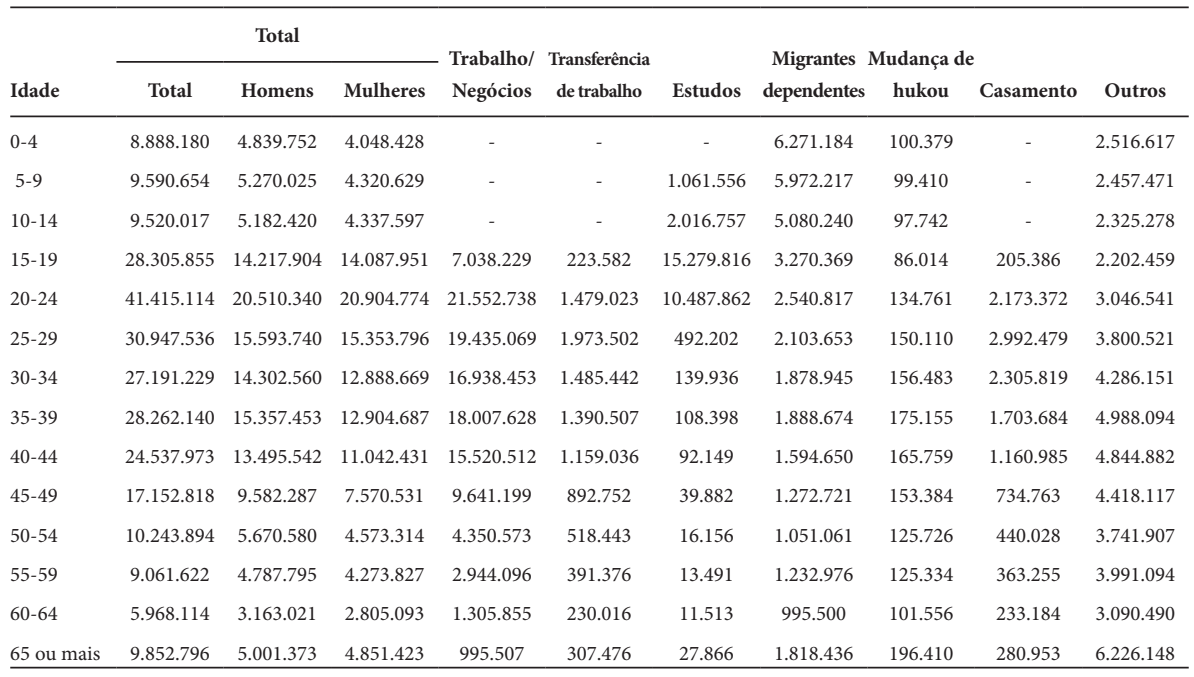

Fonte: Elaboração própria com base emdados do Censo Demográfico Chinês de 2010.

Na Figura 5 é apresentado o nível de escolaridade dos migrantes na província de residência atual, e nota-se que o número de migrantes graduados é superior àquele de analfabetos em todas as regiões, visto o baixo grau de analfabetismo entre os chineses nos últimos anos. Outro fator que pode ter contribuído para a elevação da migração de indivíduos mais qualificados é a maior possibilidade destes de conseguirem um hukou permanente, que permite a obtenção de empregos melhores, com probabilidade de receberem maiores rendas e terem melhores padrões de vida do que aqueles migrantes sem hukou, em geral, desqualificados. Porém, se levadas em consideração todas as faixas de escolaridade entre os migrantes, o maior percentual é daqueles que estudam e/ou param de estudar na transição do ensino fundamental para o ensino médio (52\%), seguidos daqueles que têm apenas o ensino básico (18\%).

As províncias que receberam o maior número de migrantes analfabetos foram Zheijiang (23.547 indivíduos), Shanghai (17.671) e Guangdong (13.411 migrantes), sendo a primeira e a terceira o destino mais escolhido por aqueles que têm apenas o nível primário de educação, 22\% e 19\% dos migrantes, respectivamente. Porém, essas províncias também atraem indivíduos qualificados, sendo que o fluxo de migrantes graduados para Shanghai ultrapassou 55 mil, e Guangdong recebeu 45.609 migrantes com nível superior de educação. 
Figura 5 - Nível de escolaridade dos migrantes por província, 2010

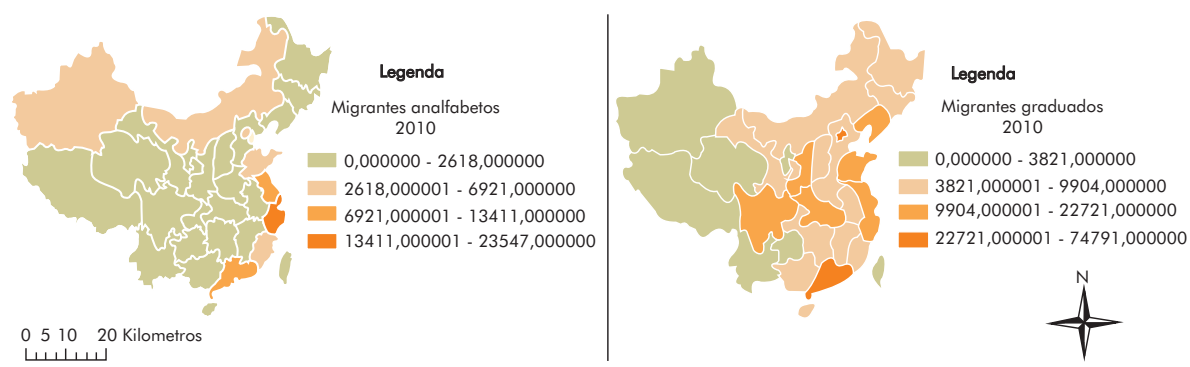

Fonte: Elaboração própria com base em dados do Censo demográfico chinês de 2010.

A capital chinesa, Beijing, foi o destino da maior parte dos indivíduos graduados (74.791 migrantes), e também do maior percentual de migrantes com pós-graduação (27\%), seguido de Shanghai, com 20\% dos migrantes pós-graduados.

Deve-se salientar que, por terem mais incentivos e receberem maiores investimentos industriais, as províncias da região leste atraem indivíduos com melhores formações e também cidadãos com baixa qualificação profissional. No entanto, as outras regiões chinesas não conseguem oferecer tantos incentivos à população devido aos baixos investimentos realizados, o que acaba gerando êxodo dessas localidades para outras mais dinâmicas e com melhores oportunidades.

\section{CONSIDERAÇÕES FINAIS}

Neste trabalho abordou-se o tema da migração em busca de melhores empregos e renda na China e as disparidades socioeconômicas entre as regiões rurais e urbanas do país, à luz do pensamento dos clássicos do desenvolvimento econômico. Por meio da discussão realizada pode-se concluir que as diferenças regionais existentes poderão ser amenizadas caso haja um planejamento na distribuição dos investimentos entre as regiões.

Como salientado por Lewis (1969), para que o salário se eleve além do nível de subsistência, é necessário que o excedente de mão de obra seja esgotado. Ou seja, é necessário que haja acumulação de capital e, a partir disso, ocorra um planejamento para melhor distribuição da oferta de mão de obra "ilimitada” por todo o território do país. Tal planejamento regional é de fundamental importância para melhor alocação dos investimentos entre as regiões. $\mathrm{O}$ investimento em capital focado nas províncias menos favorecidas poderá amenizar os problemas da concentração da urbanização na região costeira (região leste) e das desigualdades regionais na China. 
Essa discussão está de acordo com o $12^{\circ}$ Plano quinquenal chinês, adotado em 2011, e que dá as diretrizes estratégicas ao país até 2015. Desde 2011, segundo Roach (2011) e Neves (2012), o país está adotando um conjuntode metas que favorece o setor de serviços que depende mais de mão de obra, ou seja, é intensivo em trabalho. A China vem seguindo um plano detalhado para o desenvolvimento de setores que operam com transações em grande escala, como o comércio atacadista e varejista, logística de transporte doméstico e cadeia de suprimentos, saúde e lazer, que oferecem um potencial muito maior de criação de empregos. Com o foco de reduzir as taxas de desemprego e as diferenças das realidades socioeconômicas entre as zonas urbanas e rurais, esse plano está se desvinculando do modelo manufatureiro e exportador que, até então, liderava o crescimento da China.

Nesse mesmo plano quinquenal estão inseridas políticas de incentivo à elevação dos níveis educacionais da população voltados para a ciência e a tecnologia. A ideia é que maior qualificação da mão de obra favorecerá pequenas e médias empresas de alta tecnologia, que produzirão com cada vez mais valor agregado. Essa política auxiliará na qualificação da mão de obra chinesa e, no próximo plano quinquenal, o país poderá incentivar a formação de profissionais cada vez mais especializados para a modernização dos setores mais arcaicos.

O desenvolvimento e a modernização das províncias menos dinâmicas as capacitarão a oferecer oportunidades antes inexistentes. Com isso, o inchaço populacional não se concentrará nos grandes centros costeiros, e não haverá necessidade do sistema hukou funcionar com tanto rigor. A migração continuará acontecendo, porém, com menor intensidade, e serão deslocamentos de menores distâncias, com os trabalhadores buscando oportunidades em suas próprias províncias. A expansão de empregos não agrícola poderá ser feita via elevação do número de TVEs, gerando mais oportunidades àqueles que, por algum motivo, estão impossibilitados de se inserir nas atividades agrícolas.

Se melhorados os serviços prestados, as oportunidades e as condições de vida nas regiões menos favorecidas, haverá elevação do nível educacional e milhares de chineses poderão cogitar a possibilidade de dar seguimento aos estudos em detrimento de migrar em busca de empregos clandestinos. Porém, para que tais mudanças possam acontecer, é necessário um grande esforço tanto público quanto privado que direcione os investimentos e a criação de empregos para locais diversos. 


\section{REFERÊNCIAS}

CLARK, C. The conditions of economic progress. London: Macmillan, 1940.

ZHANG, Y.; WANG, Q. Reforming hukou will unify rights of migrants. China Daily USA, 31/07/2014. Disponível em: <http://usa.chinadaily.com.cn/2014-07/31/content_18226781. htm>. Acesso em: 18 out. 2016.

ICPSR. China Household Income Series Project. Ann Arbor: ICPRS, University of Michigan, 2002. Disponível em: <http://www.icpsr.umich.edu/icpsrweb/ICPSR/series/243>. Acesso em: 12 nov. 2013.

FAIRBANK, J. K.; GOLDMAN, M. China: uma nova história. Porto Alegre: L\&PM, 2006.

KUZNETS, S. Teoria do crescimento econômico moderno: taxa, estrutura e difusão. Rio de Janeiro: Zahar, 1974.

LEWIS, W. A. O desenvolvimento econômico com oferta ilimitada de mão-de-obra. In: LEWIS, W. A. A economia do subdesenvolvimento. Rio de Janeiro: Forence, 1969, p. 406-456.

LEWIS, W. A. Política econômica: a programação do desenvolvimento. Rio de Janeiro: Zahar, 1968.

LEWIS, W. A. The principles of economic planning. London: Unwin University Books, Ed. 2, 1965.

LEWIS, W. A. Os princípios do planejamento econômico. Rio de Janeiro: Editora Fundo de Cultura, 1960.

LIN, J. Y.; CHEN, B. Development strategy, technology choice and inequality.CCER Working Paper, China Center for Economic Research, Beijing, 2008.

LIN, J. Y.; CHEN, B. Urbanization and urban-rural inequality in china: a new perspective from the government's development strategy. Frontiers of Economics in China, v. 6, n. 1, p. 1-21, 2011.

MEDEIROS, C. A. Notas sobre o desenvolvimento econômico recente na China. São Paulo: Instituto de Estudos Avançados da Universidade Estadual de São Paulo, 2012. Disponível em: $<$ http://www.iea.usp.br/publicacoes/textos/medeiroschina.pdf/view>. Acesso em: 12 nov. 2013.

MORAIS, I. N. Desenvolvimento econômico, distribuição de renda e pobreza na China contemporânea. Tese (Doutorado em Economia) - Instituto de Economia, Universidade Federal do Rio de Janeiro, Rio de Janeiro, 2011. Disponível em: <http://www.ie.ufrj.br/images/pos-graducao/ppge/Isabela_Nogueira_de_Morais.pdf >. Acesso em: 2 out. 2013.

MULLAN, K.; GROSJEAN, P.; KONTOLEON, A. Land tenure arrangements and rural-urban migration in China.World Development, v. 39, n. 1, p. 123-133, 2011.

NABUCO, P. The hukou system and migration in China: some notes on the division of labour. Revista de Economia Contemporânea, v. 16, n. 2, p. 237-258, 2012. Disponível em: <http:// www.ie.ufrj.br/index.php/listar-paginas-rec/908-volumes-publicados/11602-volume-16-n2>. Acesso em: 8 Abr. 2013. 
NATIONAL BUREAU OF STATISTICS OF CHINA. China Statistical Yearbook 2012 (Chinese-English Edition). China Statistics Press, 2012. Disponível em: <http://www.stats.gov.cn/ english/statisticaldata/yearlydata/>. Acesso em: 9 abr. 2013.

NEVES, M. F. Análise: Plano quinquenal chinês estimula o consumo de alimentos. Folha de São Paulo, 21/07/2012. Disponível em: <http://www1.folha.uol.com.br/mercado /1123696-analise-plano-quinquenal-chines-estimula-o-consumo-de-alimentos.shtml $>$. Acesso em: 14 fev. 2014.

OURIQUES, H. R.; ANDRADE, R. S. C. A mobilidade do trabalho na China: o sistema de registro Hukou. Pesquisa \& Debate, v. 20, n. 2 (36), 2009. Disponível em: <http://www.pucsp.br/ pos/ecopol/downloads /12_08_11.pdf>. Acesso em: 8 abr. 2013.

PREBISCH, R. O desenvolvimento econômico da América Latina e seus principais problemas. Revista Brasileira de Economia, v. 3, n. 3, p. 47-111, 1949.

ROACH, S. S. Project Syndicate, 2011. Disponível em: <http://www.project-syndicate.org/commentary/china-s-turning-point $>$. Acesso em: 15 nov. 2013.

ROSENSTEIN-RODAN, P N. "Notas sobre a teoria do grande impulso". In: ELLIS, H.; WALLICH, H. (Orgs.). Desenvolvimento econômico para a América Latina. Rio de Janeiro: Fundo de Cultura, 1961.

WEN, G. Cautions on China'surbanization. World, v. 30, n. 37, p. 44, 2002.

ZHANG, K. H.; SONG, S. Rural-urban migration and urbanization in China: evidence from time-series and cross-section analyses. China Economic Review, v. 14, n. 4, p. 386-400, 2003. 